\title{
Assessment of Coastal Zone Ecological Carrying Capacity -- A Case Study of Haikou City
}

\author{
Junkuo Cao ${ }^{1}$, Weiquan Wang ${ }^{2}$, Xueping Zhang ${ }^{1, ~}{ }^{*}$, Yuzhang ${ }^{1}$ and Ziqiang Luo ${ }^{1}$ \\ ${ }^{1}$ Department of Information science technology, Hainan Normal University, Hainan, 571158, China \\ ${ }^{2}$ Department of Network management center, Hainan Medical University, Hainan, 571199, China \\ *email: zxp@hainnu.edu.cn
}

Keywords: Coastal Zone, Ecological Carrying Capacity, Evaluation Index System, AHP Model.

\begin{abstract}
Taking Haikou coastal zone as the study area, we use comprehensive evaluation method to select a number of support factors and limiting factors to determine the indicators of ecological carrying capacity. Combined the data of social economic development of Haikou, using analytic hierarchy process model, the whole evaluation system will be divided into three assessment levels, including the target layer, criterion layer and index layer. With regard to the weights of each level, we use the information entropy method to figure out automatically. Taking into account the specificity of coastal areas, as well as miniature changes in statistics process, evaluation results are grouped into five categories: little load, normal load, full load, overload, and red load. The evaluation results show that the ecological coastal zone carrying capacity of Haikou from the year 2008 to 2012 raised slightly with an average annual growth rate of $7.88 \%$, the minimum carrying capacity is about 0.17 , and the maximum carrying capacity is about 0.23 .In recent years, Haikou ecological carrying capacity is still under the normal load, and it will be further expanded if further control depends on scientific data and information.
\end{abstract}

\section{Introduction}

The coastal zone is the transitional zone where land and ocean and the atmosphere influence each other, it has three parts: the coast, the intertidal zone and the underwater shore[1]. The upper bound to the land is 200 meters contour, to the sea is -200 meters isobath[2]. In 1921, Park and Burgess used the definition of ecological carrying capacity in the area of human ecology for the first time. That means, in a special environmental condition, the highest level of the existing number of one species. Extending the definition of ecological carrying capacity, the comprehensive carrying capacity of ecological coastal zone refers to the population quantity and industrial scale that coastal area can burden in a special time and area, under some levels of technology, basing on the principle of sustainable development of coastal zone resources and environment[3][4] and the aim of sustainable development of the economy of coastal zone. The ecological coastal zone carrying capacity has two basic meanings: one is the ability of self-maintenance \& self-adjustment of coastal ecosystem, and the supply capacity of resources and environment subsystem; the other is human support ability's influence towards the ecosystem of the coastal zone[5][6].

Commonly used methods for evaluating the ecological bearing capacity of the coastal zone include: resource and demand difference method, comprehensive evaluation method, state space method and ecological footprint method, etc.. Each evaluation method has its area specialty[7]. Particularly, by the support of computer technology, analytic hierarchy process model is an effective system analysis tool in comprehensive evaluation method. The basic idea of the analytic hierarchy process is to decompose a complex coastal zone carrying capacity assessment problem into several factors, and grouped these factors into the control group, so as to form an ordered hierarchical structure, and then determine the relative importance of the factors in each level two by two, and then synthesis in hierarchy to make sure the decision factors' importance relative to the aim. 
The coastal zone ecosystem is special, complicated and open. It is a coupled system including social, economy, resources and environment. When selecting evaluation index of comprehensive carrying capacity of coastal zone, there are some principles including Objectivity, Operability , Independence and Sustainable Development to follow. As the coastal zone is an open system, its carrying capacity has dynamic itself. So the index system should not only show the current situations of the coastal zone carrying capacity, but more correctly predict the developing trend of different development stage of the coastal zone carrying capacity in the future.

Based on the above principles, in the selection of index, mainly consider four aspects of indexes: population, economy, protection, and resources[6]. Our article refer to related literature and combine the local conditions of Haikou, visit the local marine bureau expert, better in the original 14 third index, and extend them to 23 (see Table 1).

Table 1 The indicator system of ecological carrying capacity of coastal zone

\begin{tabular}{|c|c|c|c|}
\hline First index system & Second index system & Third index system & Unit \\
\hline \multirow{23}{*}{$\begin{array}{l}\text { Ecological carrying } \\
\text { capacity }\end{array}$} & \multirow{3}{*}{$\begin{array}{l}\text { Coastal population } \\
\text { index }\end{array}$} & Resident population density & person $/ \mathrm{km}^{2}$ \\
\hline & & Natural population growth rate & $\%$ \\
\hline & & Tourism population & $\begin{array}{l}\text { million } \\
\text { people }\end{array}$ \\
\hline & \multirow{8}{*}{$\begin{array}{l}\text { Coastal economic } \\
\text { index }\end{array}$} & Disposable income per capita & $¥$ \\
\hline & & Per capita GDP & $¥ /$ person \\
\hline & & GDP average annual growth rate & $\%$ \\
\hline & & $\begin{array}{c}\text { Third industry accounted for GDP } \\
\text { ratio }\end{array}$ & $\%$ \\
\hline & & Port cargo throughput & $10^{4} \mathrm{t}$ \\
\hline & & Marine industry production value & $10^{8} Y$ \\
\hline & & Million GDP energy consumption & $t / 10^{4} Y$ \\
\hline & & $\begin{array}{l}\text { Foreign investment accounted for the } \\
\text { proportion of GDP }\end{array}$ & $\%$ \\
\hline & \multirow{5}{*}{$\begin{array}{l}\text { Coastal zone } \\
\text { protection index }\end{array}$} & $\begin{array}{c}\text { Number of health technical } \\
\text { personnel }\end{array}$ & person \\
\hline & & $\begin{array}{c}\text { Research and development of GDP } \\
\text { ratio }\end{array}$ & $\%$ \\
\hline & & Patent application number & PCS \\
\hline & & $\begin{array}{l}\text { Environmental protection } \\
\text { expenditure ratio }\end{array}$ & $\%$ \\
\hline & & Per capita export & $\$ /$ person \\
\hline & \multirow{7}{*}{$\begin{array}{l}\text { Coastal zone } \\
\text { resources index }\end{array}$} & Sea area & hectare \\
\hline & & Fishery resources & $10^{4} \mathrm{t}$ \\
\hline & & Total marine fishing & $\mathrm{t}$ \\
\hline & & Per capita Road area & $\mathrm{m}^{2}$ \\
\hline & & Per capita water resources & $\mathrm{m}^{3} /$ person \\
\hline & & Per capita green area & $\mathrm{m}^{3} /$ person \\
\hline & & Million people in College & person \\
\hline
\end{tabular}

\section{Evaluation Model}

The ecological carrying capacity of system is a data that generalized in the convenience of research. It is relative value, not absolute value. So it needs to introduce a reference data, the standard value. In the process of carrying capacity evaluation, if the target $\mathrm{j}$ of the $\mathrm{i}$ is $x_{\mathrm{ij}}$, then the index data is $y_{\mathrm{ij}}$ after the raw data is standardized[6].

$$
y_{i j}=x_{i j} / \sum_{i=1}^{m} x_{i j}
$$

In the formula, $m$ refer to the number of the evaluation objects. 
In the process of evaluation, Quantitative distribution of weight coefficients according to the important degree of the object being evaluated. This article uses the information of evaluation index, using the entropy weighting method based on "difference driven" principle, prominent local differences, getting optimal weight from each sample's actual data, reflect the utility value of index information entropy, avoid man-made factors, so as to enhance objectivity and reproducibility.

Entropy weighting method of ecological carrying capacity evaluation uses standardized index data $\left(y_{\mathrm{ij}}\right)$ to determine each index's entropy $\left(e_{\mathrm{j}}\right)$, divergence $\left(h_{\mathrm{j}}\right)$ 、Weight $\left(w_{\mathrm{j}}\right)$, and the final calculation of the comprehensive carrying capacity $(\mathrm{M})$, calculation formula see (2)、(3)、(4) and (5) [5]

$$
\begin{aligned}
& e_{j}=-\frac{1}{\ln (m)} \sum_{i=1}^{m}\left(y_{i j} \ln y_{i j}\right) \\
& \boldsymbol{h}_{j}=\mathbf{1}-\boldsymbol{e}_{j} \\
& \boldsymbol{w}_{j}=\boldsymbol{h}_{j} / \sum_{j=1}^{n} \boldsymbol{h}_{j} \\
& \boldsymbol{M}_{i}=\sum_{j=1}^{n}\left(w_{j} y_{i j}\right)
\end{aligned}
$$

In the above formula, each letter has a determined meaning: m--the number of the evaluation objects, $n$--the number of evaluation index, $i$--evaluation object $i$ (or time), $j$--evaluation index $j$, $x_{\mathrm{ij}}$-the original value of evaluation object $i$ evaluation index $j, x_{\mathrm{ij}}$---the standard value of evaluation

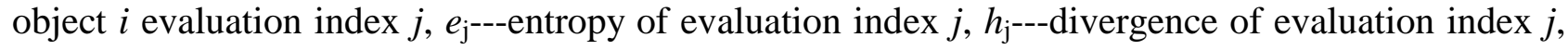
$w_{\mathrm{j}}$---weight of evaluation index $j, m_{\mathrm{i}}$--ecological carrying capacity of evaluation object $i$.

As human activities has demand for resources and environment, and their actual supply capacity, the results of the carrying capacity are normally divided into 3 circumstances[9]. When the result is less than 1, normal load; equal to 1, full load; when the result is more than 1, overload. Considering the special nature of the coastal zone and the change of the level of the comprehensive carrying capacity of the year by year, the magnitude of the change is small, the results of ecological carrying capacity are extended into five categories: little load, normal load, full load, overload, red load. Combining actual circumstances, make a tolerance for the standard of full load, its value is 0.3 , the final category results are: when $\mathrm{M} \geq 1.3$, red load; $1.3>\mathrm{M}>1.1$, overload; $0.9 \leq \mathrm{M} \leq 1.1$, full load; 0.7 $<\mathrm{M}<0.9$, normal load; $\mathrm{M} \leq 0.7$, little load.

\section{Case Study}

To investigate and analyze the coastal zone of Haikou, the evaluation time is from the year 2008 to 2012. To make sure the evaluation data has comparability and reference, basing on the evaluation index system built, the collected index data all comes from the statistical yearbook, statistical bulletin, marine bulletin, historical data,etc of Hainan province or Haikou.

\section{(1) The Study area}

Haikou is located in the northern part of Hainan province, is the capital city of Hainan province, and it has 4 districts: the Xiuying district, the Longhua district, the Qiongshan district and the Meilan district. The coastal line of Haikou is $136.2 \mathrm{~km}$ long, among which natual coastal line is $101.7 \mathrm{~km}$, $74.7 \%$ of the whole coastal line. Man-made coastal line is $34.5 \mathrm{~km}, 25.3 \%$ of the whole coastal line. The coastal zone of haikou is long and narrow, Dongzhaigang mangrove nature reserve on eastern Haikou is national nature reserve. Most of the coastal zone of Haikou belongs to the center of the city, population pressure, high road density . Besides, the coastal zone of Haikou has rich tourism resources. Driven by the tourism industry, the real estate industry developes rapidly, making the over exploitation of the coastal zone clearer. Combined the regional characteristics and human economy of Haikou, the assessment area east of Chengmai Bay, West to Puqian town, the coastal zone research 
area is the coastal land of $10 \mathrm{~km}$, which is from the coastline of Haikou City, and does not include the coastal area extending to the sea.

\section{(2) Evaluation Result}

Based on evaluation index system of the ecological coastal zone carrying capacity of Haikou, we refer to the information from 2008 to 2012 like statistical yearbook, marine bulletin of Haikou. Refer to statistical yearbook from 2009 to 2013 of Haikou, combined formula (1) - (5), based on the data of ecological carrying capacity evaluation index of Haikou, we get the entropy, divergence and weight of ecological carrying capacity's evaluation index, and get the ecological carrying capacity numerical value of Haikou from 2008 to2012 by calculation(see Fig. 1).

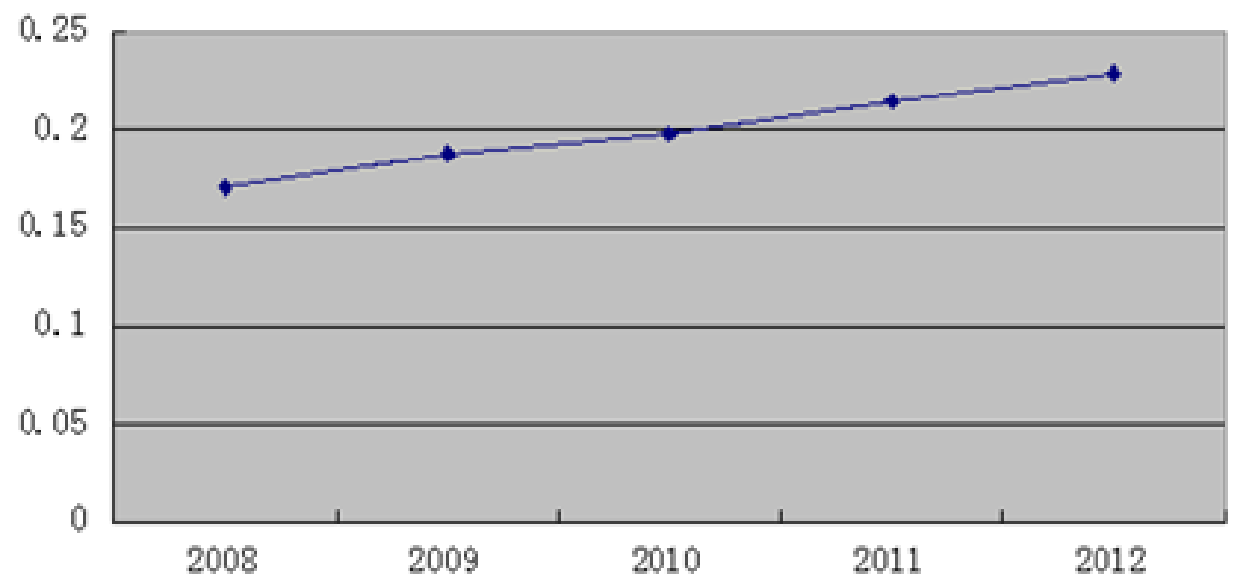

Fig. 1 The map of the coastal zone bearing capacity assessment result in Haikou

As the figure 2 shown, we know that, from 2008 to 2012, the ecological coastal zone carrying capacity didn't change a lot, the value was between 0.15 and 0.25 within five years. It was in a state of slightly increasing each year, in 2012 reaching 0.23 . Meanwhile, from the figure and data we also know that the comprehensive carrying capacity of each year was dynamic changing, and it is now in the lower limit of the normal load section of the ecological carrying capacity, the ecological carrying capacity still had enough space, and development trend was relatively flat. That means the environment can burden the development of the coastal zone recent years in its range, the whole ecosystem is healthy.

\section{Conclusion}

Taking Haikou city as an study area, we build the ecological coastal zone carrying capacity index system, use analytic hierarchy process model to divide things into different factors, and make them into group in terms of domination relationship, so as to form an ordered hierarchical structure, evaluate the current situation of the ecological carrying capacity in a comprehensive way, and use information entropy method to determine the weight of each index., index weight assignment has objectivity and rationality.

After analyzing the result of the data and integration, we can see that the ecological coastal zone carrying capacity, from 2008 to 2012, was slightly increasing, the lowest carrying capacity is 0.17 , the highest 0.23 , and the average annual growth rate is about $7.88 \%$. For the sake of the ecological coastal zone carrying capacity index module, tourism population, foreign investment accounted for the proportion of GDP, environmental protection expenditure ratio, sea area weight a lot, which needs the government's concerning. And on the other hand, the comprehensive carrying capacity is weaken to some extend under the pressure of social economic development(the pressure of social and economic development has a certain effect on the comprehensive carrying capacity). In order to maintain the stability of the coastal zone ecosystem, we need to provide the external support capacity to keep the basic balance of the comprehensive carrying capacity. 
Acknowledgments: Thanks to the support by National Natural Science Foundation (No.61363032, 61262077,61462025,61463012), International Cooperation Key Project(2012DFA11270); And this work is also supported by Hainan International Cooperation Key Project(KJHZ2014-25), Hainan Special Project for Social Development of Science and Technology(SF201436).

\section{References}

[1] Crossland C J, Kremer H H, Lindeboom H J, et al.Coastal Fluxes in the AnthroPocence. Global Change-The IGBP Series [M] SPringer: Berlin ,2005:25.

[2] Lin Tao, Xue Xiong-zhi, Lu Chang-yi.Primary study on assessing the response to coastal ecological safety[J]. Marine environmental science, 2007, 26(4):325-328.

[3] Shen Rui-sheng, Feng Yan-qing, Niu jia. Coastal zone environment problems in China and its sustainable development countermeasures[J]. Areal research and devlopment, 2005,24(3):124-127.

[4] Liu Kang, Hu Jun. The impact factors and evaluation index system of coastal zone. Journal of Ocean University of China, 2008,(4) :8-11

[5] Bishop A B, Crawford A. Carring Capacity in Regional Environmental Management. Washington: Government Printing Office, 1997.

[6] Liang Chun-Lin, Chen Chun-liang, Sun Sheng-li. A case study on the ecological carrying capacity of coastal zone.Journal Of Guangdong University of Petrochemical Technology.2013 23(3): 26-30

[7] Wei Chao, Ye Shufeng, Guo Zhangyang, etc, al. Constructing an assessment indices system to analyze integrated regional carrying capcity in the coastal zones: a case in Nantong. ACTA Ecologica Sinica, 2013,33(18):5893 -5904.

[8] Feng Wu-fa, Pan Shi-xiang, Zhang Zhao-yang. The Distributing Rules and the Change Detection of Coast-elements for Chinese Coastland[J].Journal of Geomatics Science and Technology, 2006.23(5):370-373.

[9] Wang Kai-yun, Zhou Chun-jing. Composite model system of ecological carrying capacity and its application. Beijing: Science Press, 2007. 